\section{OPEN ACCESS}

Edited by:

Gina Marie Wimp,

Georgetown University, United States

Reviewed by:

Bertrand Schatz,

Centre National de la Recherche

Scientifique (CNRS), France

Diane Lynn Larson,

United States Geological Survey,

United States

*Correspondence:

Laura A. Burkle

laura.burkle@montana.edu

Specialty section: This article was submitted to

Population and Evolutionary

Dynamics,

a section of the journal

Frontiers in Ecology and Evolution

Received: 19 February 2019

Accepted: 17 June 2019

Published: 02 July 2019

Citation:

Burkle LA, Simanonok MP, Durney JS,

Myers JA and Belote RT (2019)

Wildfires Influence Abundance,

Diversity, and Intraspecific and Interspecific Trait Variation of Native Bees and Flowering Plants Across Burned and Unburned Landscapes.

Front. Ecol. Evol. 7:252.

doi: 10.3389/fevo.2019.00252

\title{
Wildfires Influence Abundance, Diversity, and Intraspecific and Interspecific Trait Variation of Native Bees and Flowering Plants Across Burned and Unburned Landscapes
}

Laura A. Burkle ${ }^{1 *}$, Michael P. Simanonok ${ }^{1}$, J. Simone Durney ${ }^{1}$, Jonathan A. Myers ${ }^{2}$ and R. Travis Belote ${ }^{3}$

\begin{abstract}
'Department of Ecology, Montana State University, Bozeman, MT, United States, ${ }^{2}$ Department of Biology, Washington University in St. Louis, St. Louis, MO, United States, ${ }^{3}$ The Wilderness Society, Bozeman, MT, United States
\end{abstract}

Wildfire regimes are changing in the western United States, yet the ways in which wildfires influence native bees, the resources they depend on for food and nesting, or the traits that influence their interactions with plants are poorly understood. In burned and unburned areas in Montana, USA, we investigated the abundance and diversity of native bees, floral and nesting resources, nesting success, and traits of flowers and bees. In two of the three localities studied, burned areas, including areas that burned with high-severity wildfires, supported higher density and diversity of native bees and the flowers they depend on for food and larval provisioning. Burned areas also had more bare ground for ground-nesting bees and more available coarse woody debris for cavity-nesting bees than unburned areas. Moreover, cavity-nesting bees were completely unsuccessful at nesting in artificial nesting boxes in unburned areas, while nesting success was 40\% in burned areas. Mean bee intertegular distance (a trait strongly correlated with tongue length, foraging distance, and body size) was similar between burned and unburned areas. However, wildfires influenced both interspecific and intraspecific trait variation of bees and plants. Intraspecific variation in bee intertegular distance was higher in unburned than burned areas. Both interspecific and intraspecific variation in floral traits important for interactions with pollinators were generally higher in burned than unburned areas. Thus, wildfires generally increased the density and species diversity of bees and flowers as well as trait variation at both trophic levels. We conclude that wildfires - even large, high-severity wildfires-create conditions that support native bees and the resources they need to flourish, but that unburned areas maintain trait variation in landscape mosaics with heterogeneous fire conditions.

Keywords: community assembly, fire management, functional trait diversity, Northern Rockies Ecoregion, pollination, pyrodiversity, wild bees, wildfire disturbance regime 


\section{INTRODUCTION}

Among the many threats posed to biodiversity by global environmental change, changes to natural disturbance regimes are likely to have some of the most profound impacts on animals and plants and the ecosystem services they provide (Hessburg et al., 2015; Johnstone et al., 2016). Wildfires have played a critical role in maintaining the structure and function of many ecosystems worldwide (Bond and Keeley, 2005; Bowman et al., 2009). However, humans have altered natural wildfire regimes through fire suppression and climate change (Westerling et al., 2006). Despite the importance of wildfires in natural ecosystems, neither ecologists nor land managers fully understand how or why wildfire affects biodiversity and ecosystem services across complex landscapes that vary in environmental conditions (Burkle et al., 2015). This lack of understanding is particularly true for native bees, which provide pollination services essential to the recovery of plant communities in post-fire landscapes (e.g., Potts et al., 2006; Van Nuland et al., 2013; Heil and Burkle, 2019).

Several key gaps limit our understanding of how wildfires influence native bees, the resources they depend on for food and nesting, and the traits that influence their interactions with plants. First, previous studies of responses of native bees to wildfire focused primarily on floral resources, whereas the effects of wildfire on bee nesting habitat and offspring success remain poorly understood (reviewed in Koltz et al., 2018). Fire can directly cause bee mortality (Love and Cane, 2016), but it has been suggested that individuals of many groundnesting bee species may survive fires (Cane and Neff, 2011). Wildfires can open forest canopies and increase space and resources for understory flowering plants, and native bees are attracted to burned areas with abundant floral resources (e.g., Van Nuland et al., 2013). Such increases in bee and floral abundance and diversity tend to peak soon (1-5 years) after fire (Potts et al., 2003a). As forest succession proceeds, floral resources often decline, with concurrent declines in pollinator abundance (especially diet-generalist bees; Peralta et al., 2017), resulting in successional changes for both trophic levels (e.g., Potts et al., 2003a,b, 2006; Pauw, 2007; Moretti et al., 2009; Lazarina et al., 2016; Heil and Burkle, 2018). Fire and post-fire succession can also affect community composition, both taxonomically and functionally (e.g., Moretti et al., 2009; Lazarina et al., 2016, 2017; Simanonok, 2018). For bees, the quality and proximity of nesting habitat, including bare ground, stems, standing dead wood and nesting cavities, can be enhanced or reduced by fire, likely influencing bee community composition (e.g., Potts et al., 2005; Moretti et al., 2009; Lazarina et al., 2016; Simanonok, 2018). The responses of different functional groups of pollinators to fire vary in magnitude and direction, and there is high spatial variation in the effects of fire on pollinator diversity (e.g., Moretti et al., 2004; Grundel et al., 2010; Lazarina et al., 2016, 2017). Fire can subsequently affect the interactions between bees and flowering plants (Peralta et al., 2017).

Second, studies of bee and plant responses to wildfire often focus on changes in species diversity. However, changes in other key components of biodiversity-such as variation in functional traits within and among bee and plant species-can provide important insights into mechanisms of community assembly, the maintenance of biodiversity, and effects of environmental change on ecosystem functioning and services (Weiher and Keddy, 1995; McGill et al., 2006; Funk et al., 2008). Interspecific and intraspecific variation in functional traits may be especially useful for understanding the assembly, diversity, and dynamics of local communities or regions that contain individuals or species with functionally-redundant traits (Fukami et al., 2005; Spasojevic et al., 2016, 2018). For example, when fire disturbance selects for (or filters out) individuals with traits that confer tolerance to fire or increase fitness in post-fire environments, fire may cause burned communities to converge in trait values (environmental filtering), even when local species diversity remains relatively unchanged. This can result in a shift in mean trait values, lower trait variation, or both in burned relative to unburned communities (Pausas and Verdú, 2008; Cavender-Bares and Reich, 2012). Alternatively, fire may cause burned communities to diverge in trait values when it increases heterogeneity in environmental conditions or species sorting among communities (Myers et al., 2015), resulting in higher trait variation in burned relative to unburned communities. Despite the importance of traits for species interactions, the degree to which wildfire decreases or increases intraspecific vs. interspecific trait variation in two interacting trophic levels (i.e., bees and flowering plants) is poorly understood.

Third, the wildfire history and current wildfire regimes of a region also likely influence floral and nesting resources. Most studies of bee responses to fire have been conducted in fire-prone Mediterranean ecosystems or ecosystems with a long history of human-induced fire disturbance. In other regions, such as western North America, forests with a build-up of fuel have been retained by fire suppression, but the occurrence of largescale wildfires is now increasing (Hessburg and Agee, 2003; Westerling et al., 2006). These conditions result in forests with large patches of multi-storied contiguous canopy cover proximal to large areas burned by wildfires (Hessburg et al., 2015), in a region where the native bee fauna is poorly known (Reese et al., 2018). Given that bees are central place foragers with limited foraging distances from their nests (Westrich, 1996; Gathmann and Tscharntke, 2002), these large-scale wildfires may affect the quality and proximity of nesting and foraging resources in ways that differ from better-studied systems. Thus, there is a critical need to assess the effects of wildfire on native bees in this region and to begin to explore the mechanisms by which wildfire may act on bees (i.e., via effects on floral or nesting resources).

In this study, we examined how wildfire influenced the density and diversity of native bees, floral and nesting resources, nesting success, and traits of bees and flowering plants among unburned areas and areas burned by wildfires in three localities in western North America (Montana, USA). We expected to observe greater density, richness, and nesting success of bees in burned areas, reflecting-in part-greater density and richness of floral resources in post-wildfire areas (Burkle et al., 2015). Our predictions about nesting resources were more complex. We expected nesting resources (the amount of bare ground and coarse woody debris) to reflect the interplay between (a) the power of wildfire to clear understory vegetation and burn 
built-up fuel (i.e., more bare ground and less coarse woody debris) and (b) the rate and extent of regrowth of understory plants after the canopy is cleared as well as the availability of dead wood in post-fire environments (i.e., less bare ground and more coarse woody debris).

In all three of our study localities, burned areas included sites burned with a mixture of low, medium, and high wildfire severity. Given this heterogeneity in local fire conditions, we expected i) mean trait values of bees and flowering plants to differ between burned and unburned areas, and (ii) higher interspecific and intraspecific trait variation in burned than unburned areas. For bees, we predicted higher mean values of intertegular distance (the width between the wing bases on the dorsal side of the thorax) - a trait strongly correlated with tongue length, foraging distance, and body size (e.g., Cariveau et al., 2016) -in burned than unburned areas, potentially reflecting the ability of larger bees to disperse farther (Warzecha et al., 2016) after largescale wildfires. For flowering plants, we predicted higher mean values of specific leaf area in unburned areas that have more canopy cover and lower understory light levels (sensu Evans and Poorter, 2001) and where shade-tolerant species may persist (i.e., carbon-gain hypothesis; Valladares and Niinemets, 2008). For other plant traits (plant height, flower size, and floral display), we expected differences between burned and unburned areas to likely reflect the interplay between increased sunlight and decreased soil moisture in burned areas and subsequent shifts in plant resource allocation to growth and reproduction. Finally, we explored the degree to which our predictions regarding wildfire were supported across all three study localities, which vary in other key characteristics including climate and rates of forest succession following wildfire (Burkle et al., 2015).

\section{METHODS}

\section{Study System and Sampling Design}

We selected three study localities with similar recent histories of wildfire that span a regional gradient of climate, productivity, and rate of succession: Helena (low productivity and slow succession), Paradise (moderate productivity and succession), and Whitefish (high productivity and fast succession) (Burkle et al., 2015) (Figure S1). These localities also represent different forest types: ponderosa-pine forests dominate in Helena, lodgepole-pine and Douglas-fir in Paradise, and western-larch, lodgepole-pine and mixed-conifer in Whitefish. Within each locality, we identified a large wildfire perimeter within which a fire occurred between 2001 and 2007 (Table S1). Within each wildfire perimeter, we used Monitoring Trends in Burn Severity (mtbs.gov) data to select two units (15-ha each) that experienced mixed-severity fire and two units that experienced high-severity fire. We included both mixed- and high-severity units in order to (a) span the full range of fire severities created by these wildfires and (b) be able to compare differences in bees and flowering plants between mixedand high-severity units in other studies (Burkle et al., 2015; LaManna et al., in review). In this study, we focused on overall differences among burned and unburned units, where burned units included both mixed- and high-severity units. In each locality, we selected two unburned units (15-ha each) in close proximity to the wildfires (mean distance $=5.75 \mathrm{~km}$ ) with similar environmental characteristics (e.g., slope, aspect, elevation, forest type) to the burned units. All unburned units had no wildfire in at least 60 years.

Within each unit, we established nine circular sampling plots $\left(25 \mathrm{~m}\right.$ in diameter; $491 \mathrm{~m}^{2}$ ) randomly stratified using a generalized random tessellation stratified (GRTS) survey design (Kincaid and Olsen, 2011), for a total of 160 plots. Specifically, there were 54 plots each in Paradise and Whitefish and 52 plots in Helena ( 2 of the plots originally selected as unburned in Helena were burned and could not be replaced), with 16-18 unburned plots and 36 burned plots (18 mixed-severity plots and 18 high-severity plots, pooled as burned plots for analyses) in each locality. For each mixed-severity fire unit, GRTS was used to stratify the nine plots such that three were low-severity, three medium-severity, and three high-severity. The median and range of fire severities of mixed-severity plots were similar across localities; the same was true for high-severity plots (Burkle et al., 2015). Additional details on site selection and characteristics are provided in Burkle et al. (2015). These plots were used to evaluate the density, diversity, and traits of native bees, floral resources, and nesting resources across 3-4 years. Plots in Helena were surveyed twice in 2013, 12 times in 2014, 9 times in 2015, and 7 times in 2016. Plots in Paradise were observed twice in 2013, 9 times each in 2014 and 2015, and 5 times in 2016. Plots in Whitefish were observed twice in 2013, and 7 times each in 2014 and 2015. Whitefish plots were not observed in 2016. Plots from Helena and Paradise were used to investigate traits of flowers and bees. A subset of the Paradise plots (described below) were selected to investigate solitary bee nesting success.

\section{Density and Species Richness of Native Bees}

At each plot, we censused the frequency and identity of native bees by hand-netting bees observed to contact the reproductive parts of flowers for 20 min weekly throughout the growing season in each year, for a total of $1,258 \mathrm{~h}$ of observations across all plots and years. Bees were killed and identified to species or, if not yet described by keys for this region, to morphospecies. We calculated the mean bee density (i.e., average number of bees captured in a plot during a 20 -min observation period) and mean bee species richness in an observation period for each plot across all observation years. To account for differences in sampling among years, we weighted the mean value in each year by multiplying the mean value times the proportion of all censuses conducted in that year (i.e., 2013 observation values received less weight in the overall plot mean because there were fewer observations in that year). Observations were performed when there were flowers present in the plot (see Floral resources below). If observations were performed but no bees were observed, zeros were recorded and included in subsequent analyses. Bee density and richness were $\ln +1$ transformed for normality of model residuals.

\section{Floral Resources}

Across the center of each plot, we established a $25 \times 2 \mathrm{~m}$ band transect, oriented along topographic contours to minimize 
changes in elevation within transects. Within each band transect, we quantified the number of open flowers of each plant species on each observation day. We also recorded the identity of all flowering plant species in bloom in each plot on each observation day. We calculated the mean floral density and the mean flowering plant species richness on an observation day for each plot across all observation years, weighting these averages by the number of censuses in each year. Floral density was $\log +1$ transformed for normality of model residuals. With these metrics, we specifically targeted a subset of the plant community in order to quantify floral resources; the effects of wildfire on the whole plant community, including forbs (regardless of whether they were blooming), grasses and woody plants can be found in Burkle et al. (2015).

\section{Nesting Resources}

For each plot, we measured nesting resources for ground-nesting bees by quantifying percent cover of bare ground and for cavitynesting bees by quantifying coarse woody debris (CWD) (e.g., Potts et al., 2005; Grundel et al., 2010). We recorded whether bare ground or CWD was present every $10 \mathrm{~cm}$ along the diameter of each plot ( $25 \mathrm{~m}$ line transect) using a point-intercept method. In the field, we classified CWD into five diameter classes of downed logs following a modified method of Davis et al. (2016), and we grouped them together for analysis given the possibility that CWD more generally may be used as a nesting resource (e.g., Vázquez et al., 2011; Westerfelt et al., 2015; Carper and Bowers, 2017). Counts of bare ground and CWD were ln-transformed for normality of residuals.

\section{Nesting Success}

We used a subset of the plots in Paradise to assess nesting success $(N=18$ plots). This subset included 12 burned plots and 6 unburned plots. Due to logistical constraints, we were unable to measure nesting success across all three localities. Instead, we used one locality, Paradise, as a focal study site to compare nesting success among burned and unburned plots. A nesting box was affixed to the snag nearest to the center of each plot in early June 2016. When no standing snags were present, the largest piece of coarse woody debris (for 2 of 18 plots) nearest to the center of the plot was used. Nest boxes were placed with their cavity openings facing southeast and ca. one meter from the ground whenever possible. Nesting boxes were constructed out of pine or poplar, and each box had 16 drilled cavities into which cardboard bee nesting tubes were placed. Four sizes of tubes were used in each box $(3,4,5$, and $6 \mathrm{~mm})$ to maximize the number of species which could potentially nest in the boxes. Nest boxes were checked at least every other week from June through August; occupied nesting tubes were removed and replaced with unused empty tubes. Occupied tubes were then individually stored in plastic bottles with $1.5 \mathrm{~mm}$ air holes and overwintered in ambient conditions (i.e., an uninsulated outdoor structure in Bozeman, MT) from September 2016 until emergence was first noted in April 2017. Once bees began to emerge, tubes were moved to room temperature lab conditions and checked twice per week from April to August 2017 for new emergence. After emergence, bees were frozen and identified to species. For each plot, we calculated the proportion of nesting tubes from which bees emerged and nesting bee species richness.

\section{Functional Trait of Bees}

All bee individuals $(5,098)$ and species $(260)$ captured visiting flowers of selected plant species from Helena and/or Paradise (see Traits of flowering plants, below) were used for functional-trait measurement. We had time and resources to rigorously measure traits at two of the localities, and thus, traits were not measured in Whitefish. Queen bumblebees were not collected, and, thus, were not included in trait measurement. Specifically, we measured the intertegular distance (ITD, the width between the wing bases on the dorsal side of the thorax; Cariveau et al., 2016) of each individual bee because it is highly correlated with tongue length, body mass and foraging distance (Cane, 1987; Greenleaf et al., 2007; Cariveau et al., 2016). Thus, ITD represents functional traits related to interactions with flowers, reproductive success, and dispersal, among others. The ITD $(\mathrm{mm})$ of each individual was measured in ocular units with a Leica S6E microscope equipped with a calibrated reticle ruler. We calculated the mean ITD of all measured bee individuals captured from each plot (mean $N=51$ individuals per plot; range $=3-150$ individuals per plot).

\section{Functional Traits of Flowering Plants}

We selected a subset of flowering plant species present in Helena and/or Paradise for functional-trait measurement. As above, we were unable to measure traits in Whitefish. Because we were interested in flowering plants as floral resources for bees (i.e., assessing the bees perspective on flowering-plant traits), we selected those species that were observed to interact with at least one bee species and were (1) present in both Helena and Paradise or (2) present in both burned and unburned areas of Helena or Paradise. This totaled 4,099 individuals of 81 plant species.

We measured plant height, flower number, flower volume, and specific leaf area (SLA) of up to 5 randomly selected flowering individuals of each selected species, stratified across each plot, in 2017. Measurements were collected every week, alternating between Helena and Paradise, throughout the growing season to allow for measurements during peak flowering for each species. Plant height was measured from the ground to the top of the inflorescence of a flowering individual, and can be important for plant reproduction as taller plants are more visible and often attract more pollinators (e.g., Fornoff et al., 2017). The number of flowers was counted on a randomly selected inflorescence, and is a measure of plant attractiveness to pollinators (Conner and Rush, 1996; Coux et al., 2016). Flower volume was calculated from the length, width, and depth $(\mathrm{mm})$ with digital calipers, and is important for plant reproduction as larger flowers typically attract more pollinators (e.g., Stang et al., 2006). For specific leaf area (SLA), we collected a leaf from the base of each individual measured, pressed it, and weighed $(\mathrm{mg})$ to obtain dry mass. The leaf was also photographed and processed with ImageJ to measure surface area, and SLA was calculated as leaf surface area per dry mass. Leaf rachis and petiolules (for species with compound leaves) and petioles (for all species) were included in measurements of leaf area and dry mass. SLA is important for 
plant energy use and potential relative growth rate (Cornelissen et al., 2003; Vieira et al., 2013; Fornoff et al., 2017). Though SLA may not be important for pollinator attraction or rewards, we included this commonly-measured trait to gain information on the plant perspective of the potential effects of wildfire and how these effects may differ from those on plant traits important for bees. We calculated the mean trait values of plant height, flower number (square-root transformed for normality of residuals), flower volume (log-transformed), and SLA (log-transformed) across all individuals of all species measured for each plot mean $N=39$ individuals per plot; range $=5-75$ individuals per plot). We did not weight these mean trait values by their proportional abundances (i.e., community-weighted means) because traits were measured on a subset of species in each plot, though weighting was used for calculation of inter- and intra-specific variation (below).

\section{Inter- and Intra-specific Variation in Bee and Plant Traits}

To test how wildfire influenced inter- and intra-specific variation in bee and flowering plant traits, we first standardized each trait separately using Z-scores and then followed Leps et al. (2006). Specifically, to determine the interspecific variation (i.e., the among-species variation) of a trait for each plot, we calculated the weighted mean deviation of the average trait value of each species from the trait mean of all individuals of all species in the plot. For intra-specific variation, we calculated the weighted mean within-species trait variance across all species in each plot. For both inter- and intra-specific variation, weighting was incorporated as the proportion of individuals (i.e., bee individuals or flowers) of a given species in each plot. It was not possible to perform paired $t$-tests of variance for species common to burned and unburned areas of Helena or Paradise (i.e., control for potential differences in community composition) due to too few replicate species with two or more individuals in a plot. Interspecific variation in plant height, flower volume, and SLA was log-transformed, and interspecific variation in the number of flowers per inflorescence was cube-root transformed for normality of residuals. Intraspecific variation in bee ITD was cube-root transformed and intraspecific variation in all plant traits was log-transformed for normality of residuals.

\section{Statistical Methods}

We tested the effects of wildfire (burned vs. unburned), locality, and their interaction on the density and species richness of bees and flowers, nesting resources, trait values of bees and flowering plants, and inter- and intra-specific variation in traits of bees and flowering plants across plots using separate mixedeffects ANOVA models, including unit within locality as a nested random effect. Significant ANOVAs were followed by Tukey HSD tests. For plant traits, we first used a MANCOVA including all traits. Following a significant MANCOVA for mean trait values [Wilks $\lambda=0.071, F_{(12,262)}=37.45, P<0.0001$ ], interspecific variation in plant traits [Wilks $\lambda=0.29, F_{(12,262)}=12.93, P$ $<0.0001$ ], and intraspecific variation in plant traits [Wilks $\lambda=$ $\left.0.38, F_{(12,254)}=9.26, P<0.0001\right]$, we proceeded with a separate two-way ANOVA for each trait.
No statistical analyses were performed on nesting success (i.e., proportion emergence or bee species richness in nesting boxes) because no bees successfully emerged from nesting boxes in unburned plots (see section Results).

In order to help distinguish patterns in traits between burned and unburned areas due to differences in species composition from those due to shifts in trait distributions of individual species, we also performed a paired $t$-test for each trait in each of the two localities, including only the bee or plant species present in both burned and unburned areas in Helena or in Paradise (i.e., common species). There were 84 bee species in common between burned and unburned areas of Helena, 17 bee species in common in Paradise, 26 plant species in common in Helena, and 12 plant species in common in Paradise. This analysis of the effects of wildfire on matched species pairs was restricted to within each locality because there were too few species common to burned and unburned plots in both Helena and Paradise.

\section{RESULTS}

\section{Density and Species Richness of Native Bees}

Overall, we observed 281 bee species from 32 genera and 5 families (Reese et al., 2018). Across localities, dominant bee genera included Bombus (i.e., bumble bees like Bombus bifarius and B. appositus), Osmia (mason bees), Megachile (leafcutter bees), and Lasioglossum (sweat bees).

Bee density and species richness were higher in burned than unburned plots (Table 1). Moreover, these patterns differed among localities (locality $\times$ burn interaction; Table 1). Bee density was 100 and $155 \%$ higher in burned plots of Helena and Paradise, respectively, compared to unburned plots (Table 1; Figure 1A). Likewise, bee species richness was 85 and $120 \%$ higher in burned plots of Helena and Paradise, respectively, compared to unburned plots (Table 1; Figure 1B). Bee density and richness were similar in burned and unburned plots of Whitefish (Table 1; Figures 1A,B). Bee density and richness were generally higher in Helena than in Paradise or in Whitefish (Table 1; Figures 1A,B).

\section{Floral Resources}

Overall, we observed 239 flowering plant species from 128 genera and 40 families. Widespread flowering plant species included Achillea millefolium, Campanula rotundifolia, Rosa woodsii, and Symphoricarpos albus.

Floral density and species richness were higher in burned than unburned plots (Table 1), but these patterns differed among localities (locality $\times$ burn interaction; Table 1). Floral density was $510 \%$ and $450 \%$ higher in burned than unburned plots of Helena and Paradise, respectively (Table 1; Figure 1C). Floral species richness was 80 and $68 \%$ higher in burned plots of Helena and Paradise, respectively, compared to unburned plots (Table 1; Figure 1D). Floral density and richness were similar in burned and unburned plots of Whitefish (Table 1; Figures 1C,D). Floral species richness was generally highest in Helena, intermediate in Paradise, and lowest in Whitefish (Table 1; Figure 1D). 
TABLE 1 | Results of two-way ANOVAs testing the effects of wildfire (i.e., burn status as burned or unburned), locality (i.e., Helena, Paradise, or Whitefish) and their interaction on native bee density and species richness, floral density and species richness, and nesting resources (i.e., bare ground and coarse woody debris [CWD]) measured across plots.

\begin{tabular}{|c|c|c|c|c|}
\hline Response & Source & DF & $\boldsymbol{F}$ & $\boldsymbol{P}$ \\
\hline \multicolumn{5}{|l|}{ NATIVE BEES } \\
\hline \multirow[t]{3}{*}{ Bee density } & Burn status & 1,154 & 134.96 & $<0.0001$ \\
\hline & Locality & 2,154 & 83.21 & $<0.0001$ \\
\hline & Locality × Burn & 2,154 & 25.52 & $<0.0001$ \\
\hline \multirow[t]{3}{*}{ Bee richness } & Burn status & 1,154 & 159.36 & $<0.0001$ \\
\hline & Locality & 2,154 & 82.30 & $<0.0001$ \\
\hline & Locality × Burn & 2,154 & 32.02 & $<0.0001$ \\
\hline \multicolumn{5}{|c|}{ FLORAL RESOURCES } \\
\hline \multirow[t]{3}{*}{ Floral density } & Burn status & 1,154 & 62.53 & $<0.0001$ \\
\hline & Locality & 2,154 & 2.33 & 0.10 \\
\hline & Locality × Burn & 2,154 & 8.42 & 0.0003 \\
\hline \multirow[t]{3}{*}{ Floral richness } & Burn status & 1,154 & 69.20 & $<0.0001$ \\
\hline & Locality & 2,154 & 89.93 & $<0.0001$ \\
\hline & Locality $\times$ Burn & 2,154 & 40.71 & $<0.0001$ \\
\hline \multicolumn{5}{|c|}{ NESTING RESOURCES } \\
\hline \multirow[t]{3}{*}{ Bare ground } & Burn status & 1,154 & 38.89 & $<0.0001$ \\
\hline & Locality & 2,154 & 3.88 & 0.023 \\
\hline & Locality × Burn & 2,154 & 9.11 & 0.0002 \\
\hline \multirow[t]{3}{*}{ CWD } & Burn status & 1,154 & 48.81 & $<0.0001$ \\
\hline & Locality & 2,154 & 25.66 & $<0.0001$ \\
\hline & Locality × Burn & 2,154 & 6.02 & 0.0030 \\
\hline
\end{tabular}

$P$-values $<0.05$ are in boldface.

\section{Nesting Resources}

Nesting resources (bare ground \& coarse-woody debris) were higher in burned than unburned plots (Table 1), but these patterns differed among localities (locality $\times$ burn interaction; Table 1). The availability of nesting resources was higher in burned plots of Helena and Paradise compared to unburned plots, but similar between burned and unburned plots of Whitefish (Table 1). Specifically, bare ground was 195 and 330\% higher in burned plots of Helena and Paradise relative to unburned plots (Figure 1E), and CWD was 525 and 150\% higher in burned areas of Helena and Paradise (Figure 1F). Bare ground was generally higher in Helena and Paradise than in Whitefish (Table 1; Figure 1E), while CWD was higher in Whitefish than in Helena or Paradise (Table 1; Figure 1F).

\section{Nesting Success}

Bees emerged from nesting tubes in burned plots, but not from unburned plots. Across all nesting blocks, 262 nesting tubes contained offspring cells, from which 230 adult bees of 10 species emerged. Bee individuals were primarily Megachile lapponica (107) and Hoplitis albifrons argentifrons (87). No emergence was observed from any of the 47 nesting tubes collected from unburned plots that contained offspring cells, while bee emergence was $48.4 \%$ (i.e., bee offspring emerged successfully from 104 of 215 nesting tubes) in burned areas. An average of 3.0 bee species nested in boxes in burned plots.

\section{Functional Trait of Bees}

Mean ITD of all species was $28 \%$ greater in burned plots compared to unburned plots in HE, but was similar between burned and unburned plots in PV (Table 2; Figure 2A). In both Helena and Paradise, there was no difference in mean bee ITD of species common to burned and unburned areas (Helena paired $t$-test: $t=1.19, N=84$ species, $P=0.24$; Paradise paired $t$-test: $t$ $=0.37, N=17$ species, $P=0.72$ ).

Across Helena and Paradise, burned plots had 24\% higher interspecific variation in bee ITD than unburned plots (Table 3; Figure 2B). Burned plots had $47 \%$ higher intraspecific variation in bee ITD than unburned plots in Helena, but unburned plots had $40 \%$ higher intraspecific variation than burned plots in Paradise (Table 4; Figure 2C). Overall, interspecific variation in bee ITD was much higher than intraspecific variation (Figures 2B,C).

\section{Functional Traits of Flowering Plants}

Mean values of flowering plant traits generally differed between burned and unburned plots. The main effect of wildfire on the height of flowering individuals was positive: mean flowering plant height across all measured individuals and species was $16 \%$ higher in burned plots compared to unburned plots (Table 2; Figure 3A). The mean number of flowers per inflorescence was 115 and $450 \%$ higher in burned plots compared to unburned plots in Helena and Paradise, respectively (Table 2; Figure 3B). Mean flower volume was similar between burned and unburned plots in Helena, but was 193\% higher in unburned plots compared to burned plots in Paradise (Table 2; Figure 3C). Mean SLA was similar between burned and unburned plots in Helena, but was 95\% higher in unburned plots compared to burned plots in Paradise (Table 2; Figure 3D).

Mean flowering plant height of species present in both burned and unburned areas (i.e., common species) was marginally higher (by $9 \%$ ) in unburned areas compared to burned areas in Helena (paired $t$-test: $t=1.85, N=26$ species, $P=0.075$ ), and was $9 \%$ higher in unburned areas compared to burned areas in Paradise $(t$ $=2.75, N=12$ species, $P=0.019$ ). Mean number of flowers per inflorescence of common species was marginally higher (by 15\%) in burned areas compared to unburned areas in Helena (paired $t$-test: $t=1.86, \mathrm{DF}=25, P=0.074)$, but was similar between burned and unburned areas of Paradise $(t=0.93, \mathrm{DF}=1, P$ $=0.37$ ). There was no difference in flower volume of common species between burned and unburned areas in Helena (paired $t$ test: $t=1.35, \mathrm{DF}=25, P=0.19)$ or in Paradise $(t=1.46, \mathrm{DF}$ $=11, P=0.17)$. Mean SLA of common species was marginally higher (by 7\%) in unburned areas compared to burned areas in Helena (paired $t$-test: $t=1.84, \mathrm{DF}=25, P=0.078$ ), and was $99 \%$ higher in unburned areas in Paradise $(t=6.22, \mathrm{DF}=11$, $P<0.0001)$.

There were main effects of wildfire on interspecific variation in plant height and in the number of flowers per inflorescence (Table 3): across Helena and Paradise, burned plots had more variation in these traits than unburned plots (Figures 4A,B). There was similar interspecific variation in flower volume between burned and unburned plots in both Helena and Paradise (Table 3; Figure 4C). In Helena, there was no difference in 

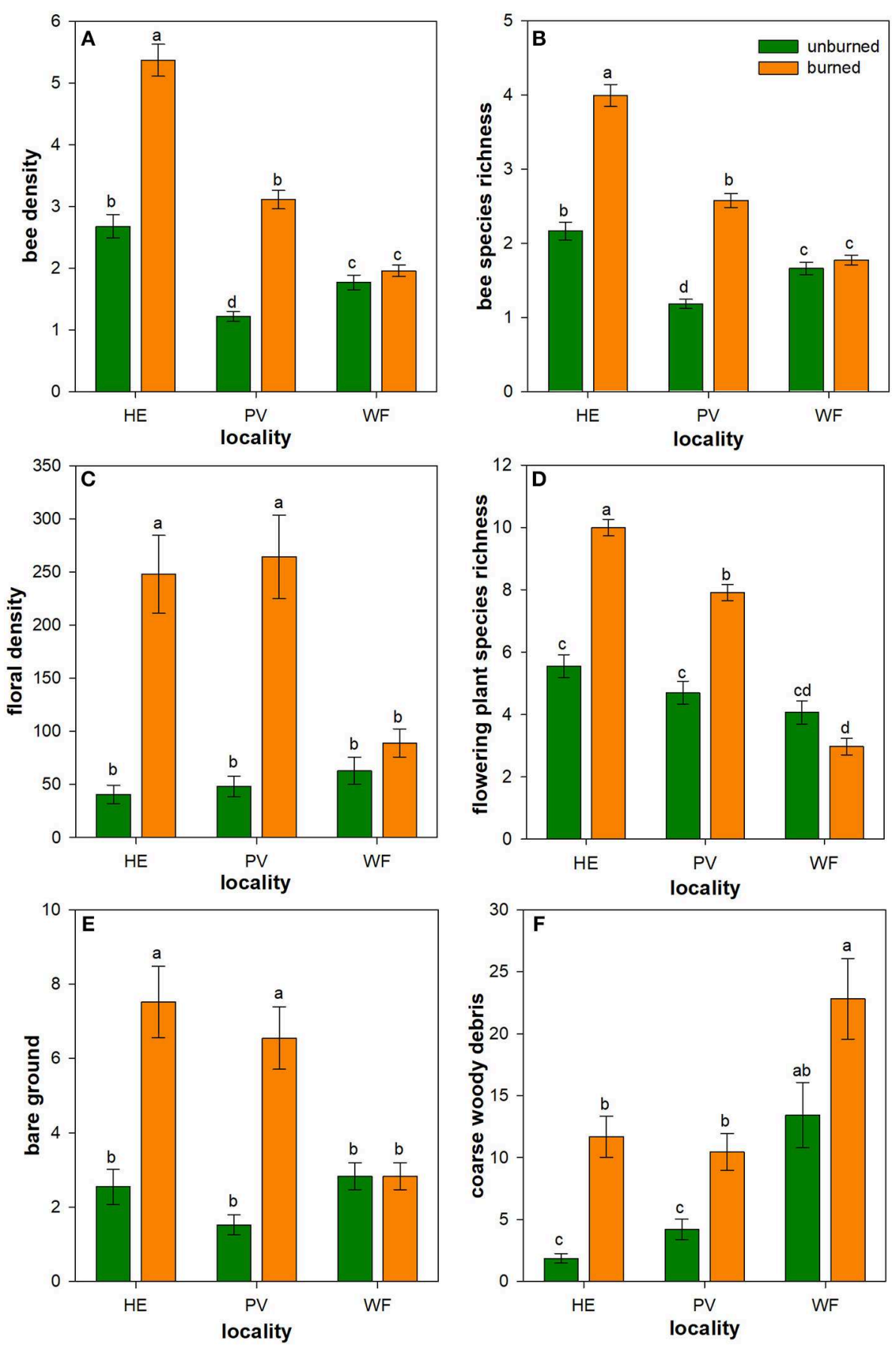

FIGURE 1 | Influence of wildfire on bees, floral resources, and nesting resources. Back-transformed least square means ( \pm 1 SE) of bee density (A), bee species richness (B), floral density (C), flowering plant species richness (D), bare ground (E), and coarse woody debris (CWD) (F) were higher in burned plots (orange) than in unburned plots (green) in Helena (HE) and Paradise (PV), but not in Whitefish (WF). Letters represent significant differences in means at $\alpha=0.05 . N=16-18$ unburned plots per locality; $N=36$ burned plots (mixed-severity and high-severity fires) per locality.

interspecific variation in SLA between burned and unburned plots, but in Paradise, interspecific variation in SLA was higher in unburned plots than burned plots (Figure 4D).

In Helena, burned and unburned plots had similar intraspecific variation in plant height, while in Paradise, intraspecific variation in plant height in burned plots was higher than in unburned plots (Table 4; Figure 4E). In both Helena and Paradise, intraspecific variation in the number of flowers per inflorescence was higher in burned plots compared to unburned plots (Table 4; Figure 4F). There was similar 
intraspecific variation in flower volume between burned and unburned plots in both Helena and Paradise (Table 4; Figure 4G). In Helena and Paradise, intraspecific variation in SLA was higher in unburned plots compared to burned plots (Table 4; Figure 4H).

Overall, interspecific variation in plant traits was greater than their intraspecific variation across plots. One exception to this pattern was the relatively greater mean intraspecific variation in SLA across plots in Helena.

TABLE 2 | Results of two-way ANOVAs testing the effects of wildfire (i.e., burn status as burned or unburned), locality (i.e., Helena or Paradise) and their interaction on the mean values of bee and plant traits of all individuals and species measured across plots.

\begin{tabular}{llrrr}
\hline Response & Source & DF & \multicolumn{1}{c}{$\boldsymbol{F}$} & $\boldsymbol{P}$ \\
\hline BEE TRAITS & & & & \\
Bee intertegular distance & Burn status & 1,95 & 13.71 & $\mathbf{0 . 0 0 0 4}$ \\
& Locality & 1,95 & 41.71 & $<\mathbf{0 . 0 0 0 1}$ \\
& Locality $\times$ Burn & 1,95 & 11.17 & $\mathbf{0 . 0 0 1 2}$ \\
PLANT TRAITS & & & & \\
Plant height & Burn status & 1,102 & 8.47 & $\mathbf{0 . 0 4 4}$ \\
& Locality & 1,102 & 4.51 & $\mathbf{0 . 0 3 6}$ \\
& Locality $\times$ Burn & 1,102 & 0.14 & 0.71 \\
Flowers per inflorescence & Burn status & 1,102 & 97.61 & $<\mathbf{0 . 0 0 0 1}$ \\
& Locality & 1,102 & 5.95 & $\mathbf{0 . 0 1 6 4}$ \\
& Locality $\times$ Burn & 1,102 & 8.56 & $\mathbf{0 . 0 0 4 2}$ \\
Flower volume & Burn status & 1,102 & 5.34 & $\mathbf{0 . 0 2 3}$ \\
& Locality & 1,102 & 10.71 & $\mathbf{0 . 0 0 1 5}$ \\
& Locality $\times$ Burn & 1,102 & 9.86 & $\mathbf{0 . 0 0 2 2}$ \\
Specific leaf area & Burn status & 1,102 & 118.87 & $<\mathbf{0 . 0 0 0 1}$ \\
& Locality & 1,102 & 245.08 & $<\mathbf{0 . 0 0 0 1}$ \\
& Locality $\times$ Burn & 1,102 & 61.63 & $<\mathbf{0 . 0 0 0 1}$ \\
& & & &
\end{tabular}

P-values $<0.05$ are in boldface.

\section{DISCUSSION}

Areas burned by wildfires supported assemblages of native bees with greater density and species diversity than unburned areas in two of the three study localities. In these two localities, we also observed greater density of floral resources, species diversity of floral resources, and nesting resources in burned areas, indicating that wildfire acts to enhance multiple aspects of habitat important for bee success. Higher bee success in

TABLE 3 | Results of two-way ANOVAs testing the effects of wildfire (i.e., burn status as burned or unburned), locality (i.e., Helena or Paradise) and their interaction on the mean interspecific variation in bee and plant traits of all individuals and species measured across plots.

\begin{tabular}{|c|c|c|c|c|}
\hline Response & Source & DF & $\boldsymbol{F}$ & $\boldsymbol{P}$ \\
\hline \multicolumn{5}{|l|}{ BEE TRAITS } \\
\hline \multirow[t]{3}{*}{ Bee intertegular distance } & Burn status & 1,95 & 5.17 & 0.025 \\
\hline & Locality & 1,95 & 29.97 & $<0.0001$ \\
\hline & Locality $\times$ Burn & 1,95 & 0.058 & 0.81 \\
\hline \multicolumn{5}{|l|}{ PLANT TRAITS } \\
\hline \multirow[t]{3}{*}{ Plant height } & Burn status & 1,102 & 8.48 & 0.0044 \\
\hline & Locality & 1,102 & 0.39 & 0.53 \\
\hline & Locality × Burn & 1,102 & 3.12 & 0.081 \\
\hline \multirow[t]{3}{*}{ Flowers per inflorescence } & Burn status & 1,102 & 57.87 & $<0.0001$ \\
\hline & Locality & 1,102 & 10.30 & 0.0018 \\
\hline & Locality × Burn & 1,102 & 0.72 & 0.40 \\
\hline \multirow[t]{3}{*}{ Flower volume } & Burn status & 1,102 & 0.32 & 0.57 \\
\hline & Locality & 1,102 & 12.34 & 0.0007 \\
\hline & Locality × Burn & 1,102 & 1.34 & 0.25 \\
\hline \multirow[t]{3}{*}{ Specific leaf area } & Burn status & 1,102 & 12.81 & 0.0005 \\
\hline & Locality & 1,102 & 41.29 & $<0.0001$ \\
\hline & Locality $\times$ Burn & 1,102 & 14.22 & 0.0003 \\
\hline
\end{tabular}

$P$-values $<0.05$ are in boldface.
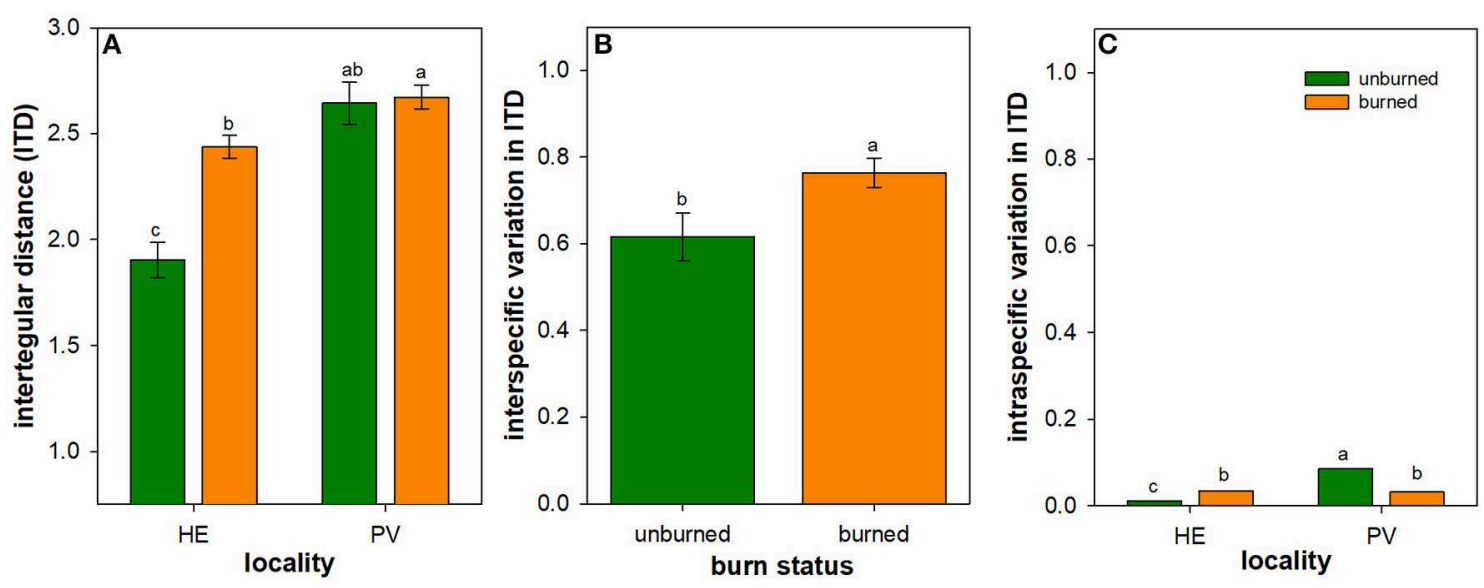

FIGURE 2 | Influence of wildfire on a bee trait and its intraspecific and interspecific variation. Least square mean ( \pm 1SE) bee intertegular distance (ITD) (in mm) (A), and back-transformed least square mean interspecific (B) and intraspecific (C) variation in bee ITD across all individuals of all species measured in burned (orange) and unburned (green) plots. Scaling is consistent between $\mathbf{( B , C )}$ for ease of comparison. Only the main effect of burn status is illustrated in panel B due to the lack of interactive effect between locality and burn status in interspecific variation in ITD (Table 3). Letters represent significant differences in means at $\alpha=0.05$. $N=16-18$ unburned plots per locality; $N=36$ burned plots (mixed-severity and high-severity fires) per locality. 
TABLE 4 | Results of two-way ANOVAs testing the effects of wildfire (i.e., burn status as burned or unburned), locality (i.e., Helena or Paradise) and their interaction on the mean intraspecific variation in bee and plant traits of all individuals and species measured across plots.

\begin{tabular}{|c|c|c|c|c|}
\hline Response & Source & DF & $\boldsymbol{F}$ & $P$ \\
\hline \multicolumn{5}{|l|}{ BEE TRAITS } \\
\hline \multirow[t]{3}{*}{ Bee intertegular distance } & Burn status & 1,88 & 0.52 & 0.47 \\
\hline & Locality & 1,88 & 47.02 & $<0.0001$ \\
\hline & Locality $\times$ Burn & 1,88 & 53.81 & $<0.0001$ \\
\hline \multicolumn{5}{|l|}{ PLANT TRAITS } \\
\hline \multirow[t]{3}{*}{ Plant height } & Burn status & 1,102 & 22.62 & $<0.0001$ \\
\hline & Locality & 1,102 & 1.94 & 0.17 \\
\hline & Locality $\times$ Burn & 1,102 & 8.27 & 0.0049 \\
\hline \multirow[t]{3}{*}{ Flowers per inflorescence } & Burn status & 1,102 & 62.67 & $<0.0001$ \\
\hline & Locality & 1,102 & 7.19 & 0.0086 \\
\hline & Locality $\times$ Burn & 1,102 & 7.34 & 0.0079 \\
\hline \multirow[t]{3}{*}{ Flower volume } & Burn status & 1,102 & 0.37 & 0.54 \\
\hline & Locality & 1,102 & 4.79 & 0.031 \\
\hline & Locality $\times$ Burn & 1,102 & 1.15 & 0.29 \\
\hline \multirow[t]{3}{*}{ Specific leaf area } & Burn status & 1,102 & 14.29 & 0.0003 \\
\hline & Locality & 1,102 & 3.95 & 0.049 \\
\hline & Locality $\times$ Burn & 1,102 & 1.83 & 0.18 \\
\hline
\end{tabular}

P-values $<0.05$ are in boldface.

burned areas was also confirmed by the presence of bees nesting in these areas and the complete lack of successful bee nesting in unburned areas. However, although interspecific and intraspecific trait variation of bees and plants was often higher in burned areas, representing important functional diversity, some unburned areas harbored trait variation as well, indicating that a landscape mosaic containing both burned and unburned areas represents the greatest reservoir of trait variation for both trophic levels. Given that, to our knowledge, this is one of the first studies to measure intraspecific trait variation in bees and that we found some divergent patterns between bees and flowering plants in the patterns of trait variation after wildfire, additional consideration of this topic will likely yield important insights into bee-forb interaction structure and function. Overall, despite some variability in bee and plant responses to wildfire across this wide biogeographic region in the Northern Rockies, wildfires create environmental conditions that are generally conducive to a wide variety of flowering plants and nesting habitat, which support native bees with diverse functional traits. Together, these results suggest that areas burned by wildfires likely also support more complex networks of bee-flower interactions than unburned areas.

\section{Density and Diversity of Native Bees, Floral Resources, Nesting Resources, and Nesting Success}

Our study confirms that, like previously-studied fire-prone systems (e.g., Potts et al., 2003a, 2005; Lazarina et al., 2016, 2017), the bee fauna of conifer forests of the western U.S. can benefit from wildfires, including those that burned with high severity. It is interesting to note that despite low bee density and, thus, diversity observed in unburned forests, these areas are likely harboring much of the full species pool from which bees recruit to burned areas, either by flying in or emerging from nests not destroyed by fire (sensu Love and Cane, 2016). Enhanced bee density, diversity, and nesting success in burned areas was accompanied by floral and nesting habitat, suggesting that both of these resources contribute to bee success after wildfire. The fact that both bare ground (supporting ground-nesting bee species) and coarse woody debris (supporting cavity-nesting bee species) were higher in burned compared to unburned areas indicates that species in these two major functional groups of bees had the potential to establish reproductive populations in burned areas, potentially contributing to the enhanced interspecific variation in ITD observed in burned areas (see section discussion below).

Whitefish, the locality for which we observed no differences in native bee diversity or in floral or nesting resources between burned and unburned areas, is also where forest succession is rapid. Young trees already dominate many burned areas in Whitefish (Burkle et al., 2015), suggesting that the window of time conducive to native bees after wildfire, if any, is short in this region and had passed before our sampling began. Such areas with rapid tree regeneration deserve additional investigation, particularly in the years immediately following wildfire, to better understand the effects on native bees.

\section{Traits of Bees}

Bees in Helena were, on average, bigger (i.e., higher intertegular distance; proxy for body size, Cariveau et al., 2016) in burned plots compared to unburned plots, while they were similarly sized regardless of wildfire in Paradise, indicating that wildfires in some environmental contexts may select for larger bees. For example, bee species with larger body sizes and thus longer potential flight ranges to reach the center of a large burn may be advantageous in the Helena landscape. This result is especially interesting in light of the pattern that Helena harbored smaller bees than Paradise overall, perhaps related to Helena's lower productivity. Given that the mean ITD of individuals of common bee species were similar between burned and unburned areas of Helena, we can conclude that the overall effect of wildfire on bee body size was driven by differences in species composition between burned and unburned areas (LaManna et al. unpublished data), with burning selecting for species with larger body size, and not recruitment of especially large individuals. Thus, it is likely that the environmental conditions important for bees are strongly contrasting between burned and unburned areas of Helena, and differential species sorting by body size is occurring. In particular, bumble bees (Bombus sp.) are likely contributing to these patterns as they are large bodied, requiring relatively large quantities of nectar and pollen for individual and colony success, and thus may be less likely to inhabit unburned areas. By contrast, the similar ITD profiles between burned and unburned areas in Paradise may indicate that recruiting into burned areas was relatively easier for bee species with smaller body sizes. Alternatively, it is possible the species pool present in Paradise simply has few small-bodied species, and thus the body size profiles of burned plots more closely reflects those of unburned plots. These differences between Helena and Paradise may also be indicative of the slower speed of succession in Helena (which 

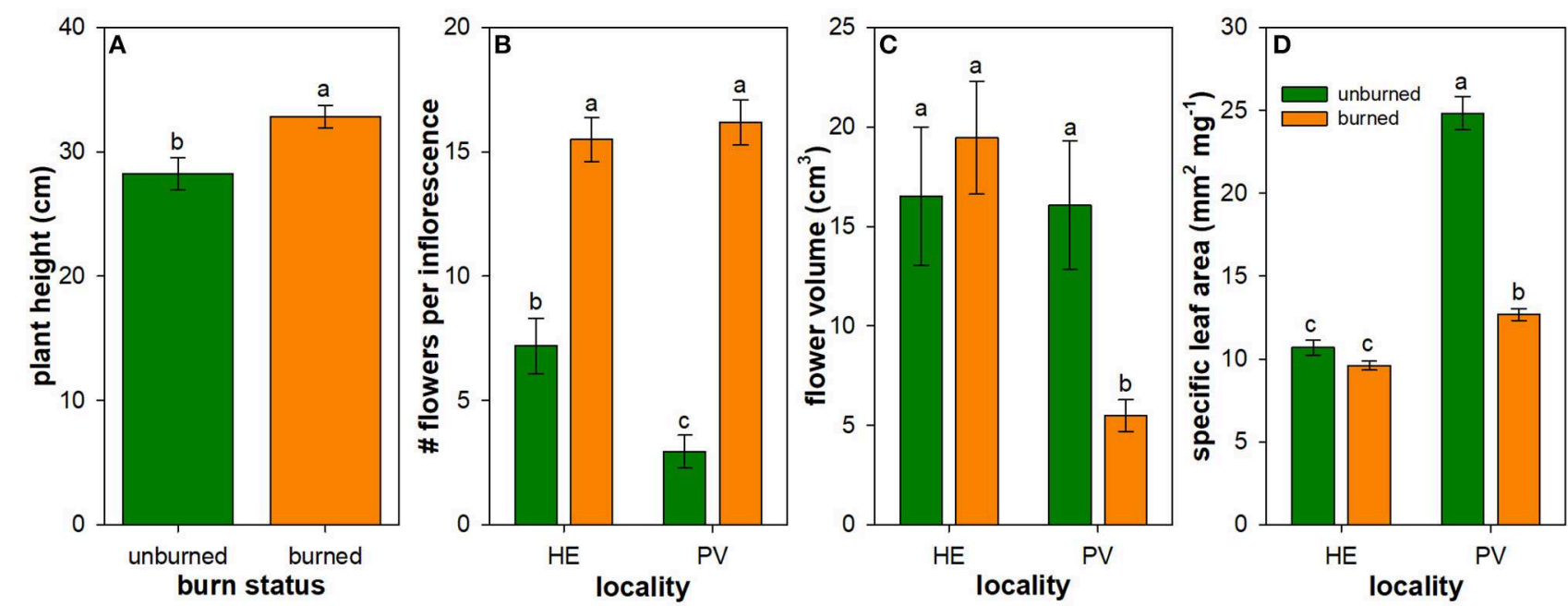

FIGURE 3 | Influence of wildfire on plant traits: plant height (A), number of flowers per inflorescence (B), flower volume (C), and specific leaf area (D). Least square mean ( \pm 1SE) plant traits across all individuals of all species measured in burned (orange) and unburned (green) plots. Back-transformed least square means are shown for number of flowers per inflorescence, flower volume, and specific leaf area (SLA). Only the main effect of burn status is illustrated in panel A due to the lack of interactive effect between locality and burn status on plant height (Table 3 ). Letters represent significant differences in means at $\alpha=0.05$. $N=16-18$ unburned plots per locality; $N=36$ burned plots (mixed-severity and high-severity fires) per locality.

is very dry and unproductive; trees have not regrown, Burkle et al., 2015) compared to Paradise (which is wetter and more productive), and it is possible that the difference in bee size observed in Helena may attenuate with time.

Across localities, there was higher interspecific variation in bee body size in burned areas compared to unburned areas, suggesting that these post-wildfire landscapes pose a less restrictive environmental filter to native bees than do unburned landscapes. This pattern is consistent with the patterns in bee species richness that we observed, albeit weaker, and confirms that burned landscapes provide more conducive habitat to a wider range of bee species than unburned landscapes. Interestingly, however, Helena and Paradise displayed contrasting patterns in the effect of wildfire on intraspecific variation in bee body size, with higher withinspecies body size variation in burned communities in Helena but higher variation in unburned communities in Paradise. While the overall magnitude of intraspecific variation was small relative to that of interspecific variation, these patterns in intraspecific variation in bee body size have important implications for interactions with flowers, including pollination effectiveness (Willmer and Finlayson, 2014). Furthermore, higher betweenindividual variation in the body size of a bee species can allow the population to be more generalized in foraging even if individuals remain specialized, resulting in more links per species (i.e., higher degree) in a community-level interaction network (sensu Bolnick et al., 2011). Higher average degree across species would result in a more-connected interaction network that would, in theory, be more robust to disturbances, species losses, and other environmental changes (e.g., Dunne et al., 2002; Memmott et al., 2004). Thus, in Paradise, where bee density and richness is particularly low in unburned areas, the relatively high intraspecific variation in body size may allow for the maintenance of bee-flower interaction networks and continued pollination services. These findings carry weight as this is one of the first studies to evaluate intraspecific trait variation in bees at the community level, and additional studies in this vein are warranted (Classen et al., 2017; Rumeu et al., 2018).

\section{Traits of Plants}

Wildfire influenced plant traits important for pollination and for plant growth (i.e., SLA). Across Helena and Paradise, plants in burned areas were taller and had more flowers per inflorescence than in unburned areas, while in Paradise only, plants in unburned areas had larger flowers and higher specific leaf area. These results suggest that post-wildfire conditions promote tall plants and flower production. After wildfire has cleared the canopy in previously forested areas, sunlight and open space are initially plentiful, allowing the establishment of a dense and diverse understory flowering plant community (e.g., Swanson et al., 2011). However, once established, there is likely competition for light and selection for taller plants (e.g., Selaya et al., 2008; Butterfield and Callaway, 2013). Because we found that plant individuals of common species were taller in unburned areas, species sorting for taller plant species may be particularly strong in burned areas. With adequate sunlight in burned areas, plants likely achieve a resource status that permits reproduction (e.g., Kilkenny and Galloway, 2008), and resources are allotted to flower production and reproduction. In Helena, the enhanced floral displays in burned areas seem to be due to a combination of both species composition (selection for species with larger floral displays) and plant-level resource allocation (individuals of common species had marginally more flowers per inflorescence), while in Paradise, the pattern appeared to be mainly driven by 


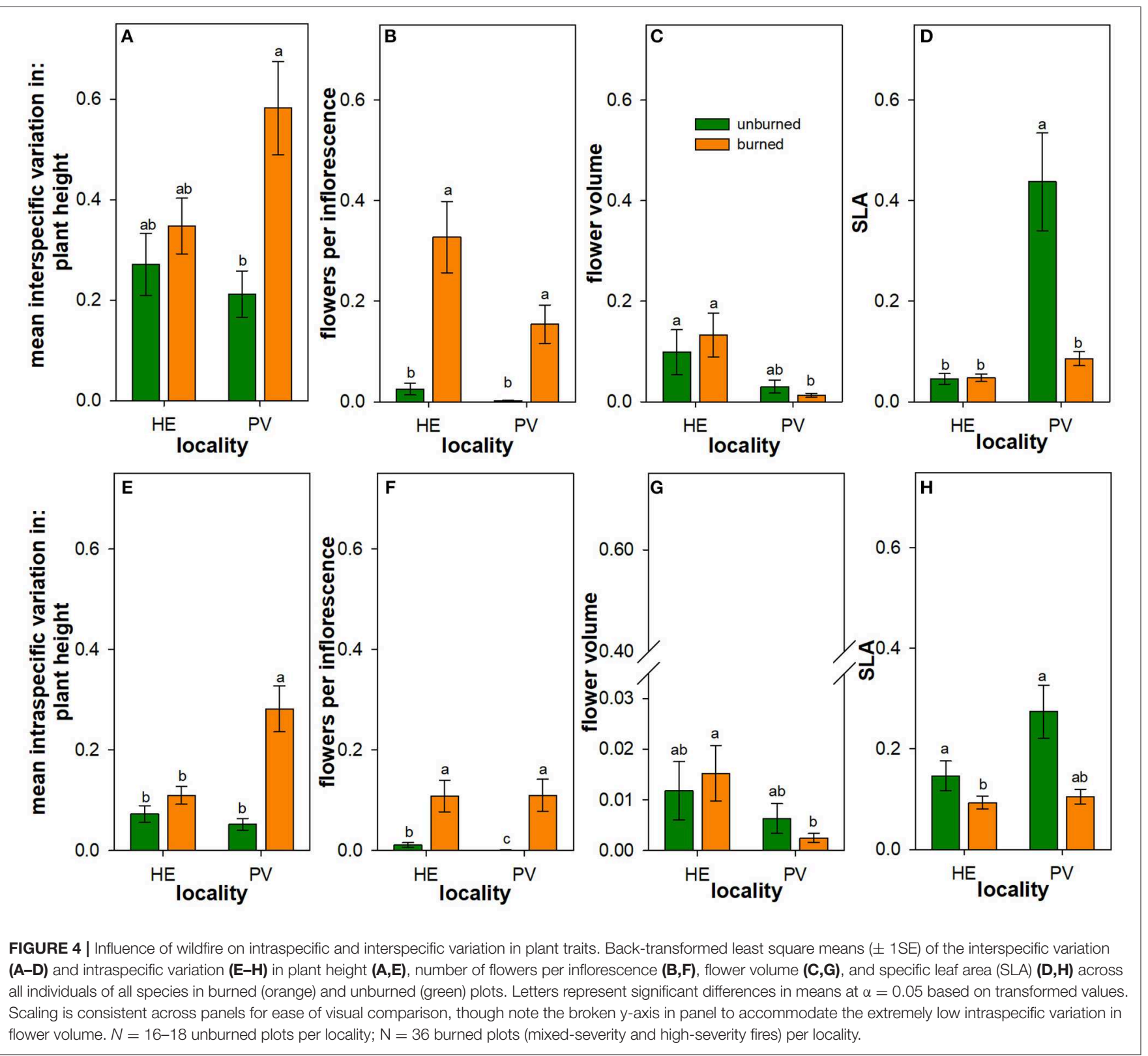

species composition. Likewise, the pattern of smaller flowers in burned areas of Paradise appeared to be driven by species composition, not individuals of common species producing smaller flowers in burned areas. Because burned areas in Paradise may be particularly hotter and drier relative to unburned areas, it is possible that sorting of species with small flowers occurs because flowers can be very expensive in terms of the water budget of a plant (e.g., Galen et al., 1999; Galen, 2000; Carroll et al., 2001). The higher SLA in unburned areas of Paradise is consistent with plants growing in low light conditions (e.g., Björkman, 1981), and the physiological responses of individuals of common species contributed to this pattern, though we cannot rule out differences in species composition between burned and unburned areas as well [i.e., potential for shade-tolerant species with higher SLA in unburned areas; (Valladares and
Niinemets, 2008)]. The lack of difference in flower size and SLA between burned and unburned areas of Helena may indicate that the environmental conditions influencing these traits are more similar between burned and unburned areas of Helena than they are in Paradise, that species composition swamps out any signal in these traits, or that the relatively unproductive conditions of Helena impose stronger selection on these traits at the regional scale compared to any selective effects of fire at more local scales.

Across localities, burned plots had more interspecific variation in plant height and flowers per inflorescence than unburned plots, indicating that these burned areas posed a less restrictive environmental filter to flowering plants-based on these traitsthan unburned areas. Again, these patterns are consistent with patterns in flowering plant species richness. By contrast, the high inter- and intraspecific variation in SLA in unburned areas of 
Paradise suggests that the conditions here permit species and individuals with a wide range of values for this trait. Similar to the patterns in interspecific variation, intraspecific variation in plant height (in Paradise only) and in flowers per inflorescence was higher in burned areas than in unburned areas, and thus may help promote complexity and robustness in plant-pollinator networks after wildfire. The lack of differences in interspecific variation in flower size between burned and unburned areas may point to a lack of species sorting based on this trait, or trade-offs with other traits for which there is stronger sorting. In addition, the lack of differences in intraspecific variation in flower size between burned and unburned areas may indicate similar strengths of evolutionary selection for consistency (or lack thereof) in flower size within species regardless of community and environmental context (e.g., Cresswell, 1998).

\section{Summary of Bee and Plant Traits}

Like bees, interspecific variation in plant traits was generally greater than their intraspecific variation across plots, though the relative effects of wildfire were of similar magnitude between bees and plants for both inter- and intraspecific variation. While bees have potentially greater dispersal abilities (flying), plants have seed banks that allow them to recruit immediately after fire (Keeley and Fotheringham, 2000), potentially contributing to the general consistency of wildfire's effects on trait variation across trophic levels. One exception to this pattern was the relatively greater mean intraspecific variation in SLA compared to interspecific variation in SLA across plots in Helena.

\section{Implications for Land Management}

Ecologists have long recognized the importance of fire in maintaining species diversity, composition, and structure of forests (Larson, 2016). In recent decades, fire policy has begun to shift from full suppression tactics to management and use. However, few fires are allowed to burn as managed wildfires (North et al., 2015), and public communications of fire is still mostly negative (e.g., Jacobson et al., 2001; Donovan and Brown, 2007). Our work provides insights into fire's role in maintaining plant and pollinator diversity across landscapes. Fire increases the diversity and abundance of flowering plants and pollinators, likely within a window of time post-wildfire related to the system-specific rate of succession. Nonetheless, unburned areas near recent fires support pollinator traits

\section{REFERENCES}

Belote, R. T. (2015). “Contemporary patterns of burn severity heterogeneity from fires in the Northwestern U.S.," in Proceedings of the Large Wildland Fires Conference, eds R. E. Keane, M. Jolly, and R. Parsons, K. Riley (Fort Collins, CO: U.S. Department of Agriculture, Forest Service, Rocky Mountain Research Station), 252-256.

Björkman, O. (1981). "Responses to different quantum flux densities," in Physiological Plant Ecology I: Responses to the Physical Environment Encyclopedia of Plant Physiology, eds O. L. Lange, P. S. Nobel, C. B. Osmond, and H. Ziegler (Berlin, Heidelberg: Springer Berlin Heidelberg), 57-107. important for the maintenance of landscape-scale trait diversity, and this remains true despite variable land-use, climate, and community composition across our study wildfires. Therefore, landscape mosaics of adjacent unburned and burned lands likely lead to overall species diversity and ecological function (Belote, 2015). Forest and fire management goals should include objectives aimed at maintaining this landscape heterogeneity (Hessburg et al., 2015).

\section{DATA AVAILABILITY}

The datasets generated for this study are available on request to the corresponding author.

\section{AUTHOR CONTRIBUTIONS}

LB, RB, and JM conceived of the study. LB, MS, and JD collected the data. LB analyzed the data and wrote the first manuscript draft. All authors contributed to manuscript revisions.

\section{FUNDING}

The National Science Foundation (DEB 1256788 and 1256819 to LB, RB, and JM) and the Joint Fire Science Program Graduate Research Innovation Award (to MS) provided financial support.

\section{ACKNOWLEDGMENTS}

We thank F. Ambrose, E. Baker, B. Bode, L. Clark, J. Cutter, E. Ehrlich, T. Hall, L. Hamburg, L. Heil, C. Herron-Sweet, G. Hoffman, M. Lavin, S. Lewis, B. Malotky, P. Mitchell, J. Neville, C. Qubain, R. Quire, E. Reese, L. Roberts, M. Rockwell, E. Sawyer, A. Starcheski, C. Seymour, C. Welch, and J. Wray for help in the field and lab, M. Spasojevic for insightful discussions on functional traits, and to E. Reese, T. Griswold, C. Delphia, S. Burrows, J. Gibbs, H. Ikerd, M. Orr, and K. Wright for bee species identifications.

\section{SUPPLEMENTARY MATERIAL}

The Supplementary Material for this article can be found online at: https://www.frontiersin.org/articles/10.3389/fevo. 2019.00252/full\#supplementary-material

Bolnick, D. I., Amarasekare, P., Araújo, M. S., Bürger, R., Levine, J. M., Novak, M., et al. (2011). Why intraspecific trait variation matters in community ecology. Trends Ecol. Evol. 26, 183-192. doi: 10.1016/j.tree.2011.01.009

Bond, W. J., and Keeley, J. E. (2005). Fire as a global 'herbivore': the ecology and evolution of flammable ecosystems. Trends Ecol. Evol. 20, 387-394. doi: 10.1016/j.tree.2005.04.025

Bowman, D. M. J. S., Balch, J. K., Artaxo, P., Bond, W. J., Carlson, J. M., Cochrane, M. A., et al. (2009). Fire in the earth system. Science 324, 481-484. doi: 10.1126/science.1163886

Burkle, L. A., Myers, J. A., and Belote, R. T. (2015). Wildfire disturbance and productivity as drivers of plant species diversity across spatial scales. Ecosphere 6, 1-14. doi: 10.1890/ES15-00438.1 
Butterfield, B. J., and Callaway, R. M. (2013). A functional comparative approach to facilitation and its context dependence. Funct. Ecol. 27, 907-917. doi: $10.1111 / 1365-2435.12019$

Cane, J. H. (1987). Estimation of bee size using intertegular span (apoidea). J. Kansas Entomol. Soc. 60, 145-147.

Cane, J. H., and Neff, J. L. (2011). Predicted fates of ground-nesting bees in soil heated by wildfire: thermal tolerances of life stages and a survey of nesting depths. Biol. Conserv. 144, 2631-2636. doi: 10.1016/j.biocon.2011.07.019

Cariveau, D. P., Nayak, G. K., Bartomeus, I., Zientek, J., Ascher, J. S., Gibbs, J., et al. (2016). The allometry of bee proboscis length and its uses in ecology. PLOS ONE 11:e0151482. doi: 10.1371/journal.pone.0151482

Carper, A. L., and Bowers, M. D. (2017). The Conservation Value of Woody Debris for Cavity-nesting Bees on Boulder County Open Space. Boulder, CO: Boulder County Open Space Final Report.

Carroll, A. B., Pallardy, S. G., and Galen, C. (2001). Drought stress, plant water status, and floral trait expression in fireweed (Epilobium angustifolium) (Onagraceae). Am. J. Bot. 88, 438-446. doi: 10.2307/2657108

Cavender-Bares, J., and Reich, P. B. (2012). Shocks to the system: community assembly of the oak savanna in a 40-year fire frequency experiment. Ecology 93, S52-S69. doi: 10.1890/11-0502.1

Classen, A., Steffan-Dewenter, I., Kindeketa, W. J., and Peters, M. K. (2017). Integrating intraspecific variation in community ecology unifies theories on body size shifts along climatic gradients. Funct. Ecol. 31, 768-777. doi: $10.1111 / 1365-2435.12786$

Conner, J. K., and Rush, S. (1996). Effects of flower size and number on pollinator visitation to wild radish, Raphanus raphanistrum. Oecologia 105, 509-516. doi: 10.1007/BF00330014

Cornelissen, J. H. C., Lavorel, S., Garnier, E., Díaz, S., Buchmann, N., Gurvich, D. E., et al. (2003). A handbook of protocols for standardised and easy measurement of plant functional traits worldwide. Aust. J. Bot. 51, 335-380. doi: 10.1071/BT02124

Coux, C., Rader, R., Bartomeus, I., and Tylianakis, J. M. (2016). Linking species functional roles to their network roles. Ecol. Lett. 19, 762-770. doi: $10.1111 /$ ele.12612

Cresswell, J. E. (1998). Stabilizing selection and the structural variability of flowers within species. Ann. Bot. 81, 463-473. doi: 10.1006/anbo.1998.0594

Davis, C. R., Belote, R. T., Williamson, M. A., Larson, A. J., and Esch, B. E. (2016). A rapid forest assessment method for multiparty monitoring across landscapes. J. Foresty 114, 125-133. doi: 10.5849/jof.14-118

Donovan, G. H., and Brown, T. C. (2007). Be careful what you wish for: the legacy of Smokey Bear. Front. Ecol. Environ. 5, 73-79. doi: 10.1890/15409295(2007)5[73:BCWYWF]2.0.CO;2

Dunne, J. A., Williams, R. J., and Martinez, N. D. (2002). Network structure and biodiversity loss in food webs: robustness increases with connectance. Ecol. Lett. 5, 558-567. doi: 10.1046/j.1461-0248.2002.00354.x

Evans, J. R., and Poorter, H. (2001). Photosynthetic acclimation of plants to growth irradiance: the relative importance of specific leaf area and nitrogen partitioning in maximizing carbon gain. Plant Cell Environ. 24, 755-767. doi: 10.1046/j.1365-3040.2001.00724.x

Fornoff, F., Klein, A.-M., Hartig, F., Benadi, G., Venjakob, C., Schaefer, H. M., et al. (2017). Functional flower traits and their diversity drive pollinator visitation. Oikos 126, 1020-1030. doi: 10.1111/oik.03869

Fukami, T., Bezemer, T. M., Mortimer, S. R., Putten, W. H., and van der (2005). Species divergence and trait convergence in experimental plant community assembly. Ecol. Lett. 8, 1283-1290. doi: 10.1111/j.1461-0248.2005.00829.x

Funk, J. L., Cleland, E. E., Suding, K. N., and Zavaleta, E. S. (2008). Restoration through reassembly: plant traits and invasion resistance. Trends Ecol. Evol. 23, 695-703. doi: 10.1016/j.tree.2008.07.013

Galen, C. (2000). High and dry: drought stress, sex-allocation trade-offs, and selection on flower size in the alpine wildflower Polemonium viscosum (Polemoniaceae). Am. Natural. 156, 72-83. doi: 10.1086/ 303373

Galen, C., Sherry, R. A., and Carroll, A. B. (1999). Are flowers physiological sinks or faucets? Costs and correlates of water use by flowers of Polemonium viscosum. Oecologia 118, 461-470. doi: 10.1007/s004420 050749

Gathmann, A., and Tscharntke, T. (2002). Foraging ranges of solitary bees. J. Anim. Ecol. 71, 757-764. doi: 10.1046/j.1365-2656.2002.00641.x
Greenleaf, S. S., Williams, N. M., Winfree, R., and Kremen, C. (2007). Bee foraging ranges and their relationship to body size. Oecologia 153, 589-596. doi: 10.1007/s00442-007-0752-9

Grundel, R., Jean, R. P., Frohnapple, K. J., Glowacki, G. A., Scott, P. E., and Pavlovic, N. B. (2010). Floral and nesting resources, habitat structure, and fire influence bee distribution across an open-forest gradient. Ecol. Appl. 20, 1678-1692. doi: 10.1890/08-1792.1

Heil, L. J., and Burkle, L. A. (2018). Recent post-wildfire salvage logging benefits local and landscape floral and bee communities. Forest Ecol. Manag. 424, 267-275. doi: 10.1016/j.foreco.2018.05.009

Heil, L. J., and Burkle, L. A. (2019). The effects of post-wildfire salvage logging on plant reproductive success and pollination in Symphoricarpos albus, a fire-tolerant shrub. Forest Ecol. Manag. 432, 157-163. doi: 10.1016/j.foreco.2018.09.013

Hessburg, P. F., and Agee, J. K. (2003). An environmental narrative of Inland Northwest United States forests, 1800-2000. Forest Ecol. Manag. 178, 23-59. doi: 10.1016/S0378-1127(03)00052-5

Hessburg, P. F., Churchill, D. J., Larson, A. J., Haugo, R. D., Miller, C., Spies, T. A., et al. (2015). Restoring fire-prone Inland Pacific landscapes: seven core principles. Landscape Ecol. 30, 1805-1835. doi: 10.1007/s10980-0150218-0

Jacobson, S. K., Monroe, M. C., and Marynowski, S. (2001). Fire at the wildland interface: the influence of experience and mass media on public knowledge, attitudes, and behavioral intentions. Wildlife Soc. Bull. 29, 929-937. Available online at: https://www.jstor.org/stable/3784420

Johnstone, J. F., Allen, C. D., Franklin, J. F., Frelich, L. E., Harvey, B. J., Higuera, P. E., et al. (2016). Changing disturbance regimes, ecological memory, and forest resilience. Front. Ecol. Environ. 14, 369-378. doi: 10.1002/fee.1311

Keeley, J. E., and Fotheringham, C. J. (2000). Role of fire in regeneration from seed Seeds 2, 311-330. doi: 10.1079/9780851994321.0311

Kilkenny, F. F., and Galloway, L. F. (2008). Reproductive success in varying light environments: direct and indirect effects of light on plants and pollinators. Oecologia 155, 247-255. doi: 10.1007/s00442-007-0903-z

Kincaid, T. M., and Olsen, A. R. (2011). spsurvey: Spatial Survey Design and Analysis. Vienna: R Foundation for Statistical Computing. Available online at: http://www.r-project.org/

Koltz, A. M., Burkle, L. A., Pressler, Y., Dell, J. E., Vidal, M. C., Richards, L. A., et al. (2018). Global change and the importance of fire for the ecology and evolution of insects. Curr. Opin. Insect Sci. 29, 110-116. doi: 10.1016/j.cois.2018. 07.015

Larson, A. J. (2016). Introduction to the article by Elers Koch: the passing of the Lolo Trail. Fire Ecol. 12, 1-6. doi: 10.4996/fireecology.1201001

Lazarina, M., Sgardelis, S. P., Tscheulin, T., Devalez, J., Mizerakis, V., Kallimanis, A. S., et al. (2017). The effect of fire history in shaping diversity patterns of flowervisiting insects in post-fire Mediterranean pine forests. Biodivers. Conserv. 26, 115-131. doi: 10.1007/s10531-016-1228-1

Lazarina, M., Sgardelis, S. P., Tscheulin, T., Kallimanis, A. S., Devalez, J., and Petanidou, T. (2016). Bee response to fire regimes in Mediterranean pine forests: the role of nesting preference, trophic specialization, and body size. Basic Appl. Ecol. 17, 308-320. doi: 10.1016/j.baae.2016.02.001

Leps, J., De Bello, F., Lavorel, S., and Berman, S. (2006). Quantifying and interpreting functional diversity of natural communities: practical considerations matter. Preslia 78, 481-501.

Love, B. G., and Cane, J. H. (2016). Limited direct effects of a massive wildfire on its sagebrush steppe bee community. Ecol. Entomol. 41, 317-326. doi: 10.1111/een.12304

McGill, B. J., Enquist, B. J., Weiher, E., and Westoby, M. (2006). Rebuilding community ecology from functional traits. Trends Ecol. Evol. 21, 178-185. doi: 10.1016/j.tree.2006.02.002

Memmott, J., Waser, N. M., and Price, M. V. (2004). Tolerance of pollination networks to species extinctions. Proc. R. Soc. Lond. Ser. B Biol. Sci. 271, 2605-2611. doi: 10.1098/rspb.2004.2909

Moretti, M., De Bello, F., Roberts, S. P. M., and Potts, S. G. (2009). Taxonomical vs. functional responses of bee communities to fire in two contrasting climatic regions. J. Anim. Ecol. 78, 98-108. doi: 10.1111/j.1365-2656.2008. 01462.x

Moretti, M., Obrist, M. K., and Duelli, P. (2004). Arthropod biodiversity after forest fires: winners and losers in the winter fire regime of 
the southern Alps. Ecography 27, 173-186. doi: 10.1111/j.0906-7590.2004. 03660.x

Myers, J. A., Chase, J. M., Crandall, R. M., and Jiménez, I. (2015). Disturbance alters beta-diversity but not the relative importance of community assembly mechanisms. J. Ecol. 103, 1291-1299. doi: 10.1111/1365-2745.12436

North, M. P., Stephens, S. L., Collins, B. M., Agee, J. K., Aplet, G., Franklin, J. F., et al. (2015). Reform forest fire management. Science 349, 1280-1281. doi: 10.1126/science.aab2356

Pausas, J. G., and Verdú, M. (2008). Fire reduces morphospace occupation in plant communities. Ecology 89, 2181-2186. doi: 10.1890/07-1737.1

Pauw, A. (2007). Collapse of a pollination web in small conservation areas. Ecology 88, 1759-1769. doi: 10.1890/06-1383.1

Peralta, G., Stevani, E. L., Chacoff, N. P., Dorado, J., and Vázquez, D. P. (2017). Fire influences the structure of plant-bee networks. J. Anim. Ecol. 86, 1372-1379. doi: 10.1111/1365-2656.12731

Potts, S., Vulliamy, B., Dafni, A., Ne'eman, G., and Willmer, P. (2003b). Linking bees and flowers: how do floral communities structure pollinator communities? Ecology 84, 2628-2642. doi: 10.1890/02-0136

Potts, S. G., Petanidou, T., Roberts, S., O’Toole, C., Hulbert, A., and Willmer, P. (2006). Plant-pollinator biodiversity and pollination services in a complex Mediterranean landscape. Biol. Conserv. 129, 519-529. doi: 10.1016/j.biocon.2005.11.019

Potts, S. G., Vulliamy, B., Dafni, A., Ne’eman, G., O’Toole, C., Roberts, S., et al. (2003a). Response of plant-pollinator communities to fire: changes in diversity, abundance and floral reward structure. Oikos 101, 103-112. doi: 10.1034/j.1600-0706.2003.12186.x

Potts, S. G., Vulliamy, B., Roberts, S., O’Toole, C., Dafni, A., Ne'eman, G., et al. (2005). Role of nesting resources in organising diverse bee communities in a Mediterranean landscape. Ecol. Entomol. 30, 78-85. doi: 10.1111/j.0307-6946.2005.00662.x

Reese, E. G., Burkle, L. A., Delphia, C. M., and Griswold, T. (2018). A list of bees from three locations in the Northern Rockies Ecoregion (NRE) of western Montana. Biodivers. Data J. 6:e27161. doi: 10.3897/BDJ.6.e27161

Rumeu, B., Sheath, D. J., Hawes, J. E., and Ings, T. C. (2018). Zooming into plantflower visitor networks: an individual trait-based approach. PeerJ 6:e5618. doi: $10.7717 /$ peerj. 5618

Selaya, N. G., Oomen, R. J., Netten, J. J. C., Werger, M. J. A., and Anten, N. P. R. (2008). Biomass allocation and leaf life span in relation to light interception by tropical forest plants during the first years of secondary succession. J. Ecol. 96, 1211-1221. doi: 10.1111/j.1365-2745.2008.01441.x

Simanonok, M. P. (2018). Plant-pollinator Network Assembly after Wildfire. Available online at: https://scholarworks.montana.edu/xmlui/handle/1/14863 (accessed February 8, 2019).

Spasojevic, M. J., Catano, C. P., LaManna, J. A., and Myers, J. A. (2018). Integrating species traits into species pools. Ecology 99, 1265-1276. doi: 10.1002/ecy.2220

Spasojevic, M. J., Turner, B. L., and Myers, J. A. (2016). When does intraspecific trait variation contribute to functional beta-diversity? J. Ecol. 104, 487-496. doi: 10.1111/1365-2745.12518

Stang, M., Klinkhamer, P. G., and van der Meijden, E. (2006). Size contraints and flower abundance determine the number of interaction in a plant-flower visitation web. Oikos 112, 111-121. doi: 10.1111/j.0030-1299.2006.14199.x
Swanson, M. E., Franklin, J. F., Beschta, R. L., Crisafulli, C. M., DellaSala, D. A., Hutto, R. L., et al. (2011). The forgotten stage of forest succession: early-successional ecosystems on forest sites. Front. Ecol. Environ. 9, 117-125. doi: $10.1890 / 090157$

Valladares, F., and Niinemets, Ü. (2008). Shade tolerance, a key plant feature of complex nature and consequences. Annu. Rev. Ecol. Evol. Syst. 39, 237-257. doi: 10.1146/annurev.ecolsys.39.110707.173506

Van Nuland, M. E., Haag, E. N., Bryant, J. A. M., Read, Q. D., Klein, R. N., Douglas, M. J., et al. (2013). Fire promotes pollinator visitation: implications for ameliorating declines of pollination services. PLoS ONE 8:e79853. doi: 10.1371/journal.pone.0079853

Vázquez, D. P., Alvarez, J. A., Debandi, G., Aranibar, J. N., and Villagra, P. E. (2011). Ecological consequences of dead wood extraction in an arid ecosystem. Basic Appl. Ecol. 12, 722-732. doi: 10.1016/j.baae.201 1.08 .009

Vieira, M. C., Cianciaruso, M. V., and Almeida-Neto, M. (2013). Plant-Pollinator coextinctions and the loss of plant functional and phylogenetic diversity. PLoS ONE 8:e81242. doi: 10.1371/journal.pone. 0081242

Warzecha, D., Diekötter, T., Wolters, V., and Jauker, F. (2016). Intraspecific body size increases with habitat fragmentation in wild bee pollinators. Landscape Ecol. 31, 1449-1455. doi: 10.1007/s10980-016-0349-y

Weiher, E., and Keddy, P. A. (1995). Assembly rules, null models, and trait dispersion: new questions from old patterns. Oikos 74, 159-164. doi: $10.2307 / 3545686$

Westerfelt, P., Widenfalk, O., Lindelöw, Å., Gustafsson, L., and Weslien, J. (2015). Nesting of solitary wasps and bees in natural and artificial holes in dead wood in young boreal forest stands. Insect Conserv. Divers. 8, 493-504. doi: 10.1111 /icad.12128

Westerling, A. L., Hidalgo, H. G., Cayan, D. R., and Swetnam, T. W. (2006). Warming and earlier spring increase western US forest wildfire activity. Science 313:940. doi: 10.1126/science. 1128834

Westrich, P. (1996). "Habitat requirements of central European bees and problems of partial habitats," in The Conservation of Bees, eds A. Matheson, S. L. Buchmann, C. O’Toole, P. Westrich, and I. H. Williams (London: Academic Press), 1-16.

Willmer, P. G., and Finlayson, K. (2014). Big bees do a better job: intraspecific size variation influences pollination effectiveness. J. Pollinat. Ecol. 14, 244-254. doi: 10.26786/1920-7603(2014)22

Conflict of Interest Statement: The authors declare that the research was conducted in the absence of any commercial or financial relationships that could be construed as a potential conflict of interest.

Copyright (C) 2019 Burkle, Simanonok, Durney, Myers and Belote. This is an openaccess article distributed under the terms of the Creative Commons Attribution License (CC BY). The use, distribution or reproduction in other forums is permitted, provided the original author(s) and the copyright owner(s) are credited and that the original publication in this journal is cited, in accordance with accepted academic practice. No use, distribution or reproduction is permitted which does not comply with these terms. 